\title{
Timo Rademacher
}

\section{Realakte im Rechtsschutzsystem der Europäischen Union}

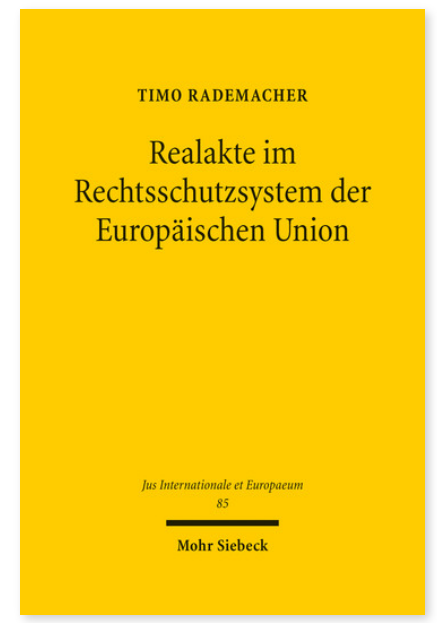

2014. XXII, 420 Seiten. JusIntEu 85

ISBN 978-3-16-153103-3

eBook PDF $119,00 €$

ISBN 978-3-16-153087-6

Leinen $119,00 €$
Das Unionsprozessrecht scheint bislang keine Handhabe gegen reales Verwaltungshandeln der EU zu bieten. Werden subjektive Rechte etwa durch Informationsakte, polizeiliches Handeln, soft law oder informale Absprachen verletzt, dann fehlt gerichtlicher Schutz. Dabei kann es nicht bleiben. Die komplex verwobenen Rechtsschutzgarantien der Grundrechtecharta, der EMRK und der allgemeinen Rechtsgrundsätze verlangen nach einer Revision des status quo, um der wachsenden Grundrechtssensibilität gerecht zu werden. Aufbauend auf einer Analyse von Judikatur und Verwaltungsrealität arbeitet Timo Rademacher zunächst die 'Ansprüche' der Rechtsschutzgarantien an die prozessuale Erfassung von Realakten heraus. Anschließend zeigt er, dass diese Ansprüche ohne Vertragsänderung erfüllbar sind: Geboten wird eine rechtsvergleichend gestützte Rekonstruktion des EU-Prozessrechts, die den Kontakt zur Gerichtspraxis wahrt und erstmals ein vollständiges System unionalen Rechtsschutzes liefert.

Timo Rademacher Timo Rademacher ist Juniorprofessor für Öffentliches Recht und neue Technologien an der Leibniz Universität Hannover.
Jetzt bestellen:

https://mohrsiebeck.com/buch/realakte-im-rechtsschutzsystem-der-europaeischen-union-9783161531033?no_cache=1 order@mohrsiebeck.com

Telefon: +49 (0)7071-923-17

Telefax: $+49(0) 7071-51104$ 